Received: 17.10 .2019

Revised: 21.11 .2019

Accepted: 20.12 .2019

DOI: $10.17804 / 2410-9908.2019 .6 .058-067$

\title{
FATIGUE FAILURE OF NATURAL COMPOSITE MATERIALS
}

\author{
V. P. Shveikin \\ Institute of Engineering Science, Ural Branch of the Russian Academy of Sciences, \\ 34 Komsomolskaya St., 620049, Ekaterinburg, Russian Federation \\ B. N. Yeltsin Ural Federal University, \\ 19 Mira St., 620002, Ekaterinburg, Russian Federation \\ iDhttps://orcid.org/0000-0002-9316-1369 هshveikin60@mail.ru \\ Corresponding author. E-mail: shveikin60@mail.ru \\ Address for correspondence: 34 Komsomolskaya St., 620049, Ekaterinburg, Russian Federation \\ Tel.: +7 (343) 3742594
}

The paper studies the fatigue characteristics of samples of low-carbon low-alloy steels, normalized and cooled from the intercritical temperature range at different rates. Fractographs of the fracture surfaces of the samples after fatigue tests are presented. The fatigue fracture surfaces are analyzed in detail. It is concluded that biphasic ferritic-martensitic steels have a higher resistance to fatigue failure as compared to steels with the ferrite-pearlite structure.

Keywords: low-carbon low-alloy steels, ferritic-martensitic steels, fracture surface, fatigue failure, ferrite-pearlite structure.

\section{Acknowledgment}

The study was performed with the use of the equipment installed at the Plastometriya collective use center affiliated to the IES UB RAS, Ekaterinburg, under the Arctic program of UB RAS, project BP 18-9-1-20.

\section{References}

1. Botvina L.R. Kinetika razrusheniya konstruktsionnykh materialov [Fracture Kinetics of Construction Materials]. Moscow, Nauka Publ., 1989. 230 p. (In Russian).

2. Kotsanda S. Ustalostnoe rastreskivanie metallov [Fatigue Cracking of Metals, transl. Pol.]. Moscow, Metallurgiya Publ., 1990. (In Russian).

3. Bronfin B.M., Shveikin V.P., Shifman A.Z. Influence of type of microstructure on fatigue resistance and fracture of low-carbon, low-alloy steel. Steel in the USSR, vol. 16, iss. 10, pp. 494-496.

4. Goritskii V.M. and Terent'ev V.F. Struktura i ustalostnoe razrushenie metallov [Structure and Fatigue-Induced Failure of Metals]. Moscow, Metallurgiya Publ., 1980. (In Russian).

5. Wasen J., Hamberg K., Karlsson B. The influence of prestrain and ageing on fatigue crack growth in a Dual-Phase Steel. Scripta Metallurgica, 1984, vol. 18, no. 3, pp. 621-624.

6. Pietrowski R., Gasse W.F., and Kenny W.D. Fatigue Properties of Renitrogenized and Dual Phase Steels. In: International Congress and Exposition, Detroit, Michigan, February 28-March 4, 1983: SAE Technical Paper Series, 1983, no. 2, pp. 1-11.

7. Romaniv O.N. Vyazkost razrusheniya konstruktsionnykh staley [Fracture Toughness of Structural Steels]. Moscow, Metallurgiya Publ., 1979. 176 p. (In Russian).

8. Potemkin A., Vikylov A., Nikitin D. Fatigue failure of materials from a position of various theories. Nauchno-metodicheskiy Elektronniy Zhurnal "Kontsept”, 2015, vol. 13, pp. 3311-3315. (In Russian). 
9. Orlov M.R., Ospennikova O.G., Avtaev V.V., Terekhin A.M., Filonova E.V. Fractography analysis of operational distructure of the gas-turbine engine high pressure rotor disk made of EP741-NP superalloy. Aviatsionnye Materialy i Technologii. 2015, no. S1 (38), pp. 5-12. (In Russian).

10. Drukarenko N.A., Kamantsev I.S., A.V.Kuznetsov, Vladimirov A.P., Khudorozhkova Yu.V. Numerical and Experimental Approaches to the Evaluation of the Fatigue Life of a Cylindrical Specimen made of the 09G2S Steel. In: AIP Conf. Proc., 2017, vol. 1915, 040010. DOI: $10.1063 / 1.5017358$. 
Подана в журнал: 17.10 .2019

УДК 620.172.25

DOI: $10.17804 / 2410-9908.2019 .6 .058-067$

\title{
ОСОБЕННОСТИ УСТАЛОСТНОГО РАЗРУШЕНИЯ ЕСТЕСТВЕННЫХ КОМПОЗИЦИОННЫХ МАТЕРИАЛОВ
}

\author{
В. П. Швейкин \\ ${ }^{1}$ Институт машиноведения Уральского отделения Российской академии наук, \\ ул. Комсомольская, 34, Екатеринбург, Российская Федераиия \\ B. N. Yeltsin Ural Federal University, \\ 19 Mira St., 620002, Ekaterinburg, Russian Federation \\ (iD https://orcid.org/0000-0002-9316-1369 ه shveikin60@mail.ru \\ Ответственный автор. Электронная почта: shveikin60@ mail.ru \\ Адрес для переписки: ул. Комсомольская, 34, г. Екатеринбург, 620049, Российская Федерация \\ Тел.: +7 (343) 3742594
}

Проведено исследование усталостных характеристик образцов малоуглеродистых низколегированных сталей в нормализованном состоянии и после охлаждения из межкритического интервала температур с различными скоростями. Приведены фрактограммы поверхности разрушения образцов после усталостных испытаний. Проведен детальный анализ зон поверхности усталостного разрушения. Сделан вывод о том, что двухфазные ферритомартенситные стали обладают более высоким сопротивлением усталостному разрушению по сравнению со сталями с феррито-перлитной структурой.

Ключевые слова: малоуглеродистые низколегированные стали, феррито-мартенситные стали, поверхность разрушения, усталостное разрушение, феррито-перлитная структура.

\section{1. Введение}

Двухфазные феррито-мартенситные стали (ДФМС), получаемые путем закалки из межкритического интервала температур, можно рассматривать как естественный композит, состоящий из мягкой пластичной ферритной матрицы и твердой структурной составляющей. Многие типы разрушений, в том числе и большинство эксплуатационных, образуются в результате усталостного нагружения $[1,2]$. В связи с этим, научный и практический интерес представляют данные по влиянию скорости охлаждения из межкритического интервала температур и последующего деформационного старения на сопротивление ДФМС усталостному разрушению. Исследование проведено на стали 05Г2С2 [3] и 05Г2Р.

\section{2. Подготовка образцов}

Применением различных режимов термообработки формировали микроструктуру: феррито-перлитную после нормализации от $1000{ }^{\circ} \mathrm{C}$, феррито-мартенситную после закалки в воде из межкритического интервала температур $\left(850{ }^{\circ} \mathrm{C}\right)$, феррито-бейнито-мартенситную после охлаждения с этой же температуры в масле. Образцы деформировали в холодном состоянии на $5 \%$, часть из них подвергали старению при $200{ }^{\circ} \mathrm{C}$ в течение 1 ч. 


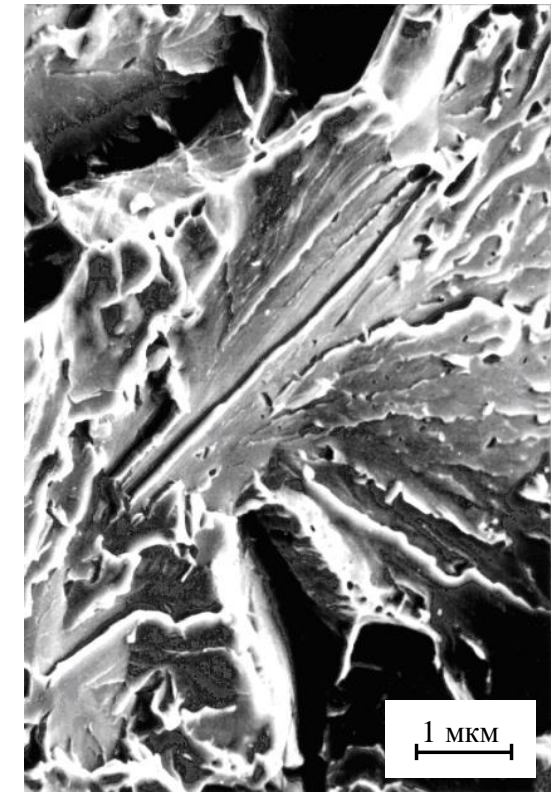

$a$

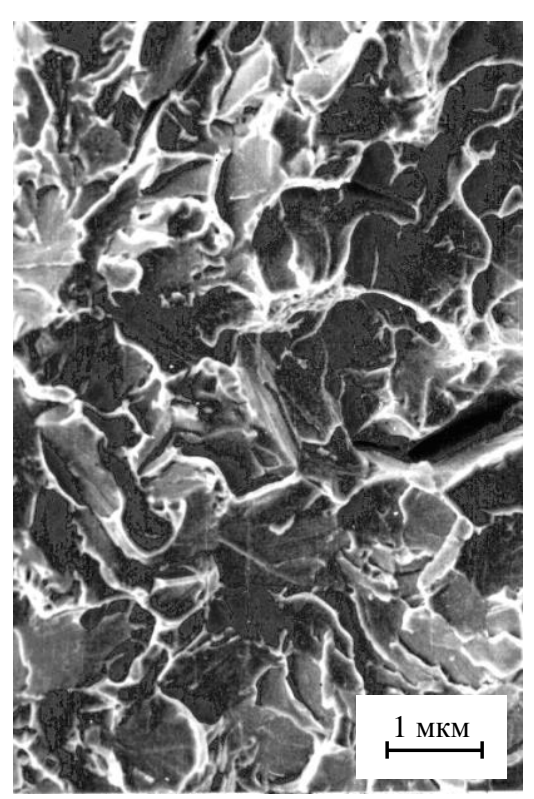

B

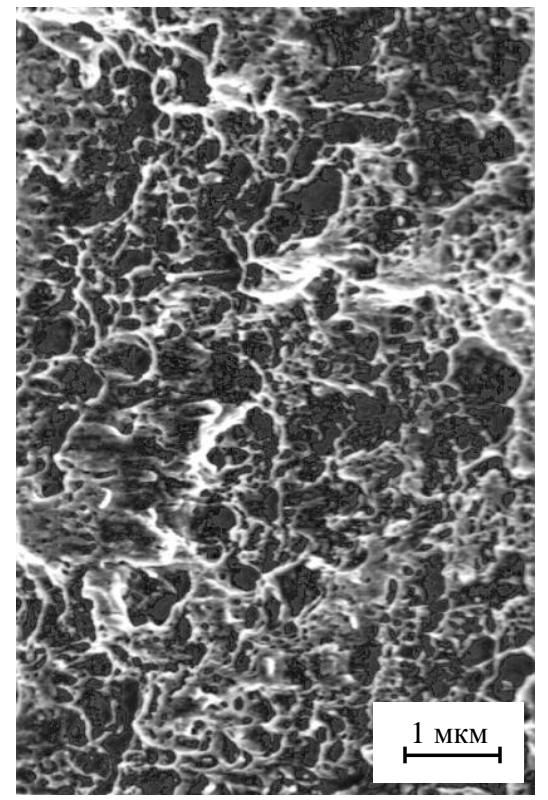

6

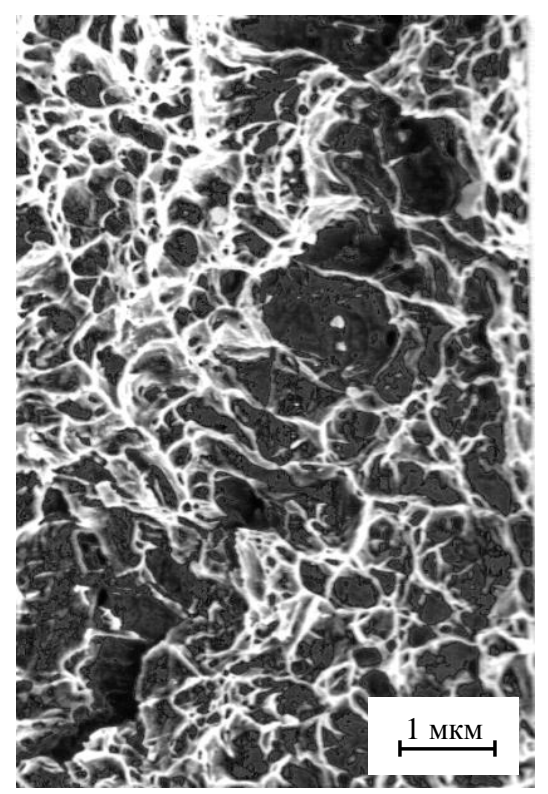

2

Рис. 1 Микрофрактограммы образцов из стали 05Г2С2 после деформации $\varepsilon=5 \%(a, \sigma)$ и последующего отпуска $200{ }^{\circ} \mathrm{C}, 1$ ч $(в, 2): a-t_{\text {исп }}=20^{\circ} \mathrm{C} ; \sigma-t_{\text {исп }}=100{ }^{\circ} \mathrm{C}$;

$$
B-t_{\text {исп }}=-20^{\circ} \mathrm{C} ; 2-t_{\text {исп }}=70^{\circ} \mathrm{C}
$$

Микрофрактограммы изломов, полученных при температурах испытания от -20 до $+100{ }^{\circ} \mathrm{C}$, приведены на рис. 1 и 2. Хрупкое состояние демонстрирует крупные фасетки скола в изломе, в то время как вязкое состояние представлено классическими мелкими ямками. 


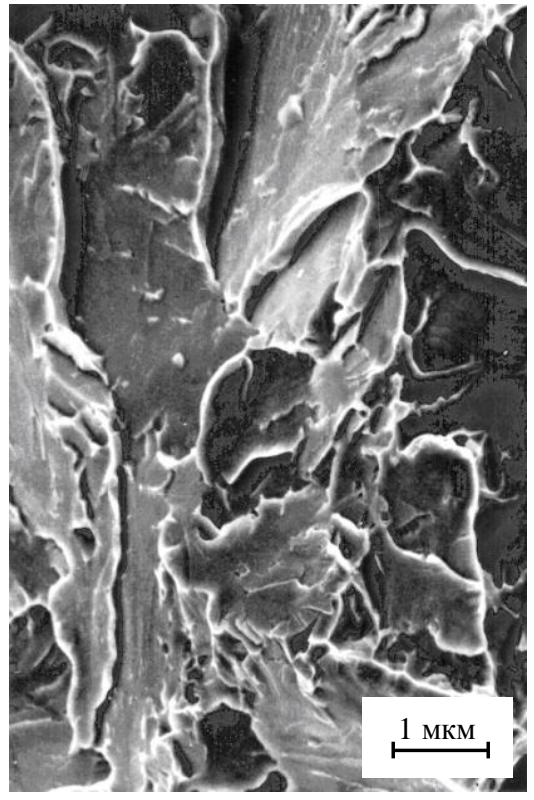

$a$

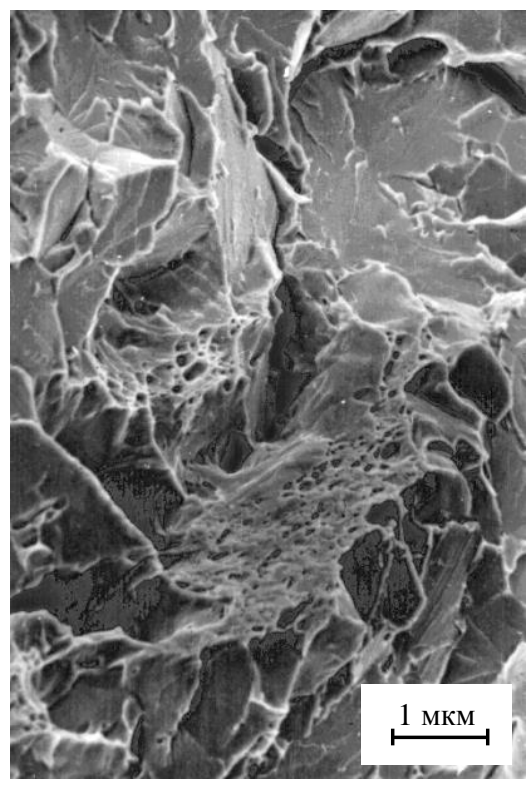

B

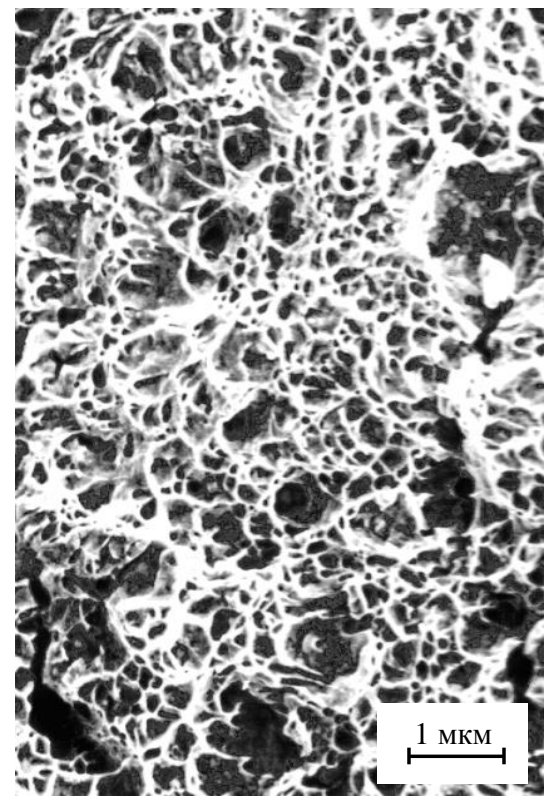

б

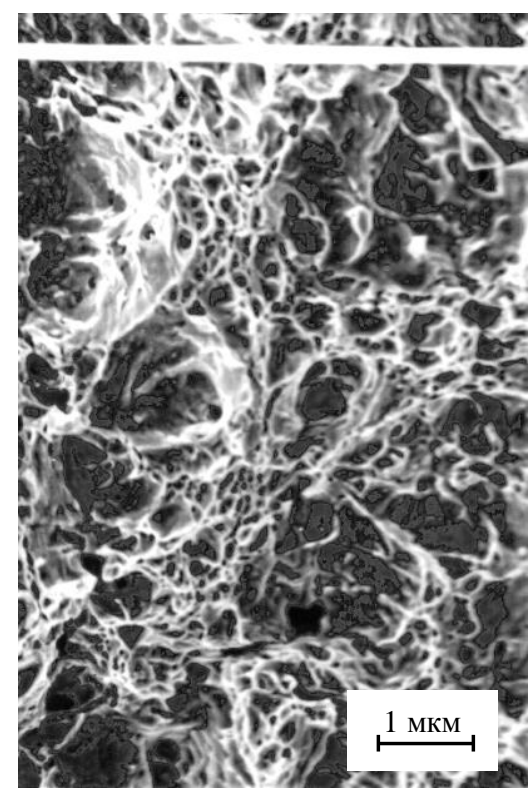

2

Рис. 2. Микрофрактограммы образцов из стали 05Г2Р после деформации $\varepsilon=5 \%(a, \sigma)$ и последующего отпуска $200{ }^{\circ} \mathrm{C}, 1$ ч $(\theta, 2): a-t_{\text {исп }}=20^{\circ} \mathrm{C} ; \sigma-t_{\text {исп }}=100{ }^{\circ} \mathrm{C}$;

$$
B-t_{\text {исп }}=-20^{\circ} \mathrm{C} ; 2-t_{\text {исп }}=50^{\circ} \mathrm{C}
$$

\section{3. Результаты исследования и их обсуждение}

Механические свойства стали после термической обработки по этим режимам, а также последующей холодной деформации растяжением на $5 \%$ и отпуска $200{ }^{\circ} \mathrm{C}, 1$ ч представлены в таблице. Следует отметить, что двухфазные материалы в состоянии без отпуска обладают низким значением условного предела текучести, который почти вдвое меньше временного сопротивления. В состоянии после небольшой пластической деформации и низкотемпературного отпуска условный предел текучести существенно возрастает, приближаясь к значению временного сопротивления. 
Прочностные свойства стали 05Г2С2 после обработок по различным режимам

\begin{tabular}{|l|c|c|c|}
\hline \multicolumn{1}{|c|}{ Режим обработки } & $\begin{array}{c}\sigma_{0,2}, \\
\text { МПа }\end{array}$ & $\begin{array}{c}\sigma_{\mathrm{B}}, \\
\text { MПа }\end{array}$ & $\sigma_{\mathrm{B}} / \sigma_{0,2}$ \\
\hline Нормализация & 380 & 580 & 1,53 \\
\hline Нормализация $+\varepsilon=5 \%+$ отпуск $200{ }^{\circ} \mathrm{C}, 1$ ч & 655 & 684 & 1,04 \\
\hline Закалка в воде от $850^{\circ} \mathrm{C}$ & 440 & 780 & 1,77 \\
\hline Закалка в масле от $850^{\circ} \mathrm{C}$ & 380 & 715 & 1,86 \\
\hline $\begin{array}{l}\text { Закалка в масле от } 850^{\circ} \mathrm{C}+\varepsilon=5 \%+\text { отпуск } \\
200^{\circ} \mathrm{C}, 1 \text { ч }\end{array}$ & 805 & 833 & 1,03 \\
\hline Охлаждение на воздухе от $850^{\circ} \mathrm{C}$ & 340 & 680 & 2,00 \\
\hline $\begin{array}{l}\text { Охлаждение на воздухе от } 850^{\circ} \mathrm{C}+ \\
\varepsilon=5 \%+\text { отпуск } 200^{\circ} \mathrm{C}, 1 \text { ч }\end{array}$ & 730 & 780 & 1,07 \\
\hline
\end{tabular}

Усталостные испытания проводили по схеме чистого изгиба при кручении на машине типа УВМ согласно ГОСТ 25.502-79. Кривые усталости для образцов из стали 05Г2С2 после различных обработок представлены на рис. 3.

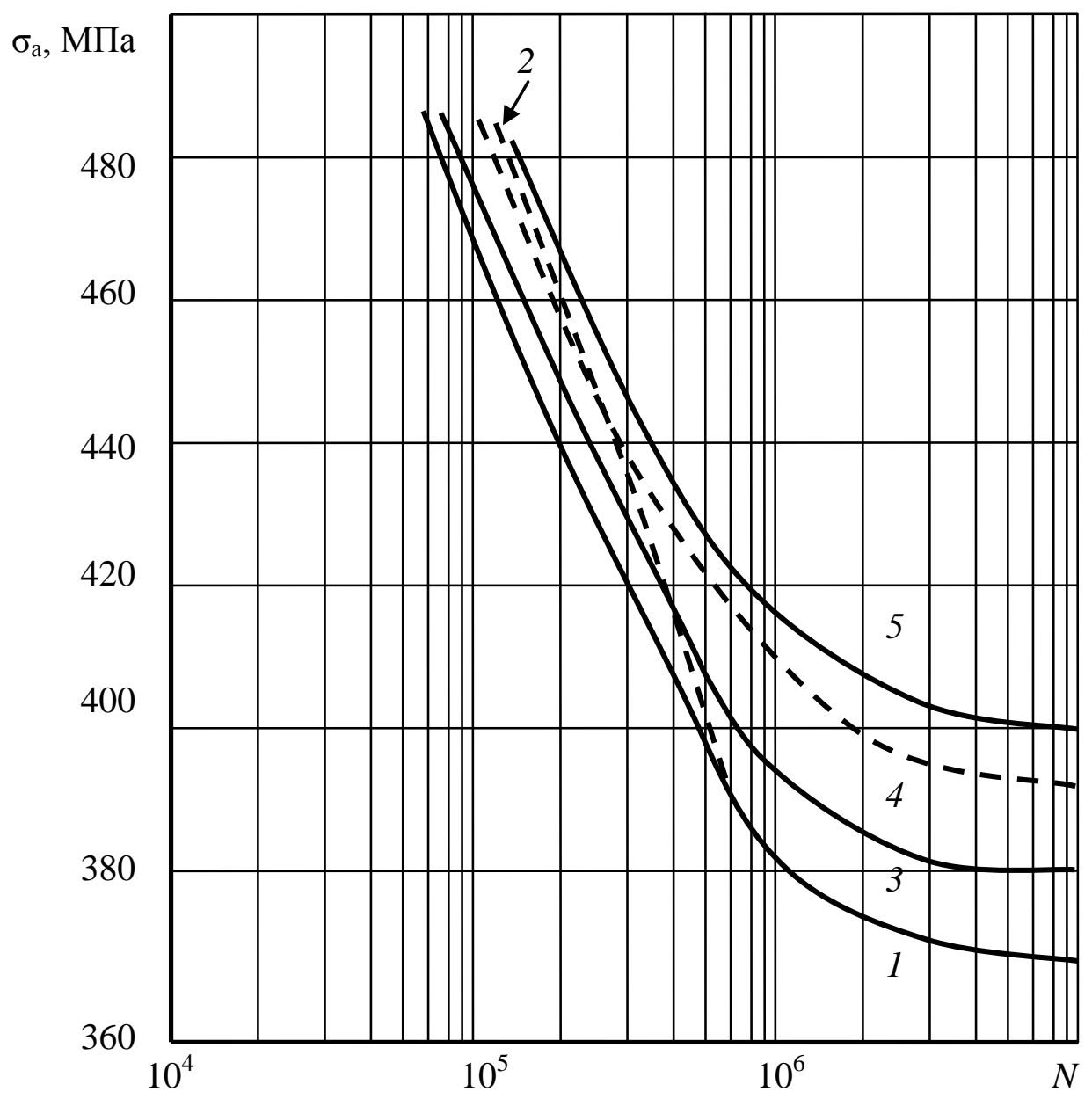

Рис. 3. Кривые усталости образцов из стали 05Г2С2: 1 - нормализация от $1000{ }^{\circ} \mathrm{C}$; 2 - нормализация от $1000{ }^{\circ} \mathrm{C}+\varepsilon=5 \%+$ отпуск $200^{\circ} \mathrm{C}, 1$ ч; 3 - охлаждение в масле от $850{ }^{\circ} \mathrm{C}$; 4 - охлаждение в масле от $850^{\circ} \mathrm{C}+\varepsilon=5 \%+$ отпуск $200{ }^{\circ} \mathrm{C}, 1$ ч; 5 - закалка в воде от $850{ }^{\circ} \mathrm{C}$ 
Сталь с феррито-мартенситной и феррито-бейнито-мартенситной структурой обладает более высоким значением предела выносливости, чем та же сталь с феррито-перлитной структурой. Однако относительное повышение предела выносливости существенно ниже, чем статических характеристик прочности (рис. 3 и таблица). Например, переход от ферритоперлитной к феррито-мартенситной структуре сопровождается повышением $\sigma_{\text {в }}$ на $25 \%$, а $\sigma_{\mathrm{w}}-$ всего лишь на $8 \%$.

Деформационное старение по указанному в таблице режиму значительно повышает величину временного сопротивления при статических испытаниях на растяжение. Например, для феррито-перлитной структуры этот прирост составляет $104 \mathrm{MПа,} \mathrm{а} \mathrm{для} \mathrm{феррито-бейнито-}$ мартенситной - 118 МПа. В то же время предел выносливости после деформационного старения в случае феррито-перлитной структуры не изменяется, а для стали с феррито-бейнитомартенситной структурой увеличился всего лишь на 10 МПа.

Такое слабое изменение предела выносливости в результате протекания предварительного деформационного старения связано, по всей видимости, со следующими обстоятельствами. Известно [4-6], что отношение временного сопротивления $\sigma_{\text {в }}$ к условному пределу текучести $\sigma_{0,2}$ коррелирует со склонностью материала к упрочнению или разупрочнению в процессе циклического нагружения. Все материалы с $\sigma_{\mathrm{B}} / \sigma_{0,2}<1,2$ разупрочняются при циклическом деформировании, тогда как материалы, для которых $\sigma_{\mathrm{B}} / \sigma_{0,2}>1,4$, циклически упрочняются. Исходя из этого положения и основываясь на данных таблицы, следует заключить, что образцы из стали 05Г2С2 со всеми типами структур, не подвергнутые деформационному старению, должны циклически упрочняться, а образцы, предварительно продеформированные и состаренные, наоборот, разупрочняться в процессе циклического нагружения.

Циклическое разупрочнение образцов, испытавших предварительное деформационное старение, может быть связано со следующими причинами. В процессе деформационного старения происходит интенсивное закрепление дислокаций атомами внедрения, приводящее к значительному возрастанию предела текучести. При последующем наложении циклической нагрузки закрепленные дислокации освобождаются от атмосфер и становятся подвижными, совершая многократное поступательное движение. Поскольку амплитуда цикла $\sigma_{a}$ значительно меньше $\sigma_{0,2}$, то деформационного упрочнения не происходит. Если же $\sigma_{a}$ соизмеримо с величиной $\sigma_{0,2}$ материала, что имеет место в нашем случае для всех обработок без предварительного деформационного старения, то происходит циклическое упрочнение.

В целях детального изучения процессов, происходящих в материале при усталостном нагружении, было проведено микрофрактографическое исследование усталостных образцов, разрушенных при различных амплитудах цикла. Анализ изломов показал, что в соответствии c [4,7] они состоят из трех участков, связанных с зарождением усталостной трещины, субкритическим ее подрастанием и быстрым доломом (рис. 4 и 5).

Установлено, что независимо от режима термической обработки площадь зоны долома увеличивается с повышением амплитуды циклической нагрузки $\sigma_{a}$. Одновременно с этим происходит некоторое смещение зоны долома по отношению к очагу разрушения в направлении, противоположном вращению во время испытания.

В случае, когда $\sigma_{a}$ минимально превышает $\sigma_{\mathrm{w}}$, трещина возникает от одного очага и общее разрушение наступает в результате роста такой трещины. При возрастании $\sigma_{a}$ увеличивается число очагов разрушения. Микротрещины, растущие из этих очагов, постепенно объединяются, образуя общий фронт. До объединения микротрещины обычно разделены вертикальными выступами, благодаря которым в изломе образуется храповый узор (рис. 5 a).

На рис. 4 представлены фрактограммы, полученные с трех зон излома усталостного образца из стали $05 Г 2 \mathrm{C} 2$ после закалки в воде от $850{ }^{\circ} \mathrm{C}$. В зоне зарождения трещины видны усталостные бороздки шириной 1-2 мкм (рис. $4 a$ ), что согласуется с данными [4]. Наряду с усталостными бороздками наблюдается и небольшое количество вторичных трещин, распространяющихся перпендикулярно по отношению к усталостной трещине. 


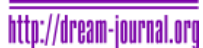

http://dream-journal.org

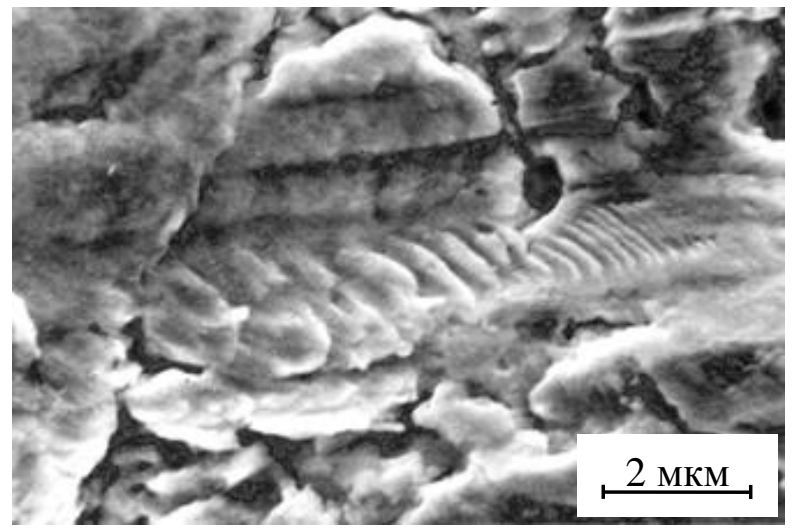

$a$

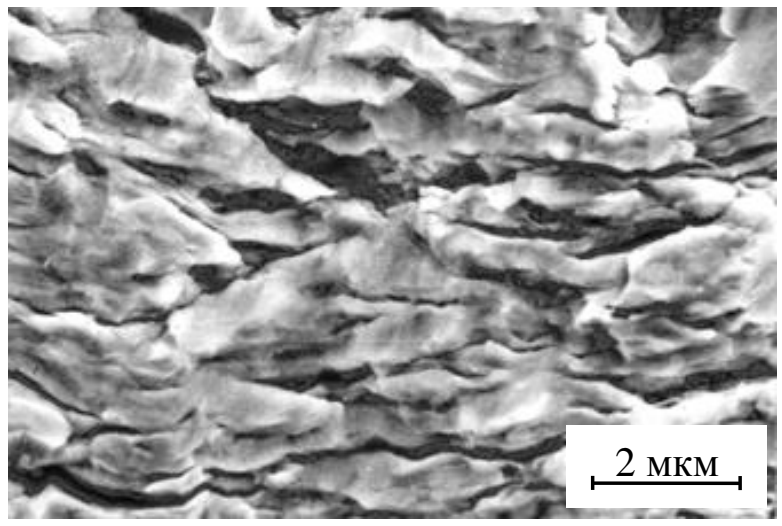

$\sigma$

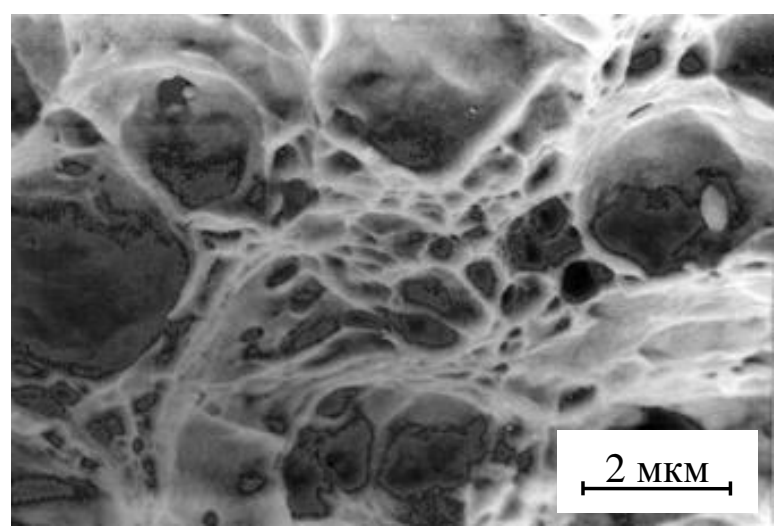

2

Рис. 4. Фрактограммы образцов стали $05 Г 2 \mathrm{C} 2$, закаленных в воде от $850{ }^{\circ} \mathrm{C}, \sigma_{a}=460 \mathrm{MПа:}$ $a$ - зона зарождения трещины; $\sigma$ - зона распространения трещины; 6 - зона долома

Вторая зона излома соответствует ускоренному развитию трещины. На этом этапе тонкие усталостные бороздки превращаются в грубые, относительно широкие светлые полосы, расположенные на крупных плато (рис. 4 б).

Плотность вторичных трещин значительно возрастает и наблюдается их четкая ориентировка вдоль фронта усталостной трещины.

Замена феррито-мартенситной структуры на феррито-бейнито-мартенситную сопровождается появлением во второй зоне излома отдельных разобщенных участков с ямочным рельефом (рис. 5 б). Эти участки соответствуют очагам однократного разрушения, возникающим у неметаллических включений. В результате повышаются энергозатраты на развитие усталостной трещины, что положительно влияет на сопротивление материала усталостному разрушению. Снижение нагрузки при циклических испытаниях расширяет зону распространения усталостной трещины и увеличивает притертость поверхности.

Независимо от режима термической обработки, зона долома имеет ямочный рельеф, характерный для вязкого разрушения при однократном нагружении (рис.4 в; 5 в). Размеры и форма ямок в зоне долома неоднородны. Наряду с крупными сферическими ямками наблюдается сетка мелких ямок, оконтуренных гребнями отрыва, что согласуется с данными [8-10]. С увеличением скорости охлаждения из межкритического интервала температур наблюдается возрастание среднего размера крупных ямок, что приводит к повышению энергозатрат на разрушение и является, по всей видимости, одной из причин роста предела выносливости (рис. 3). 
ittpr://dream-journal.or"n

http://dream-journal.org

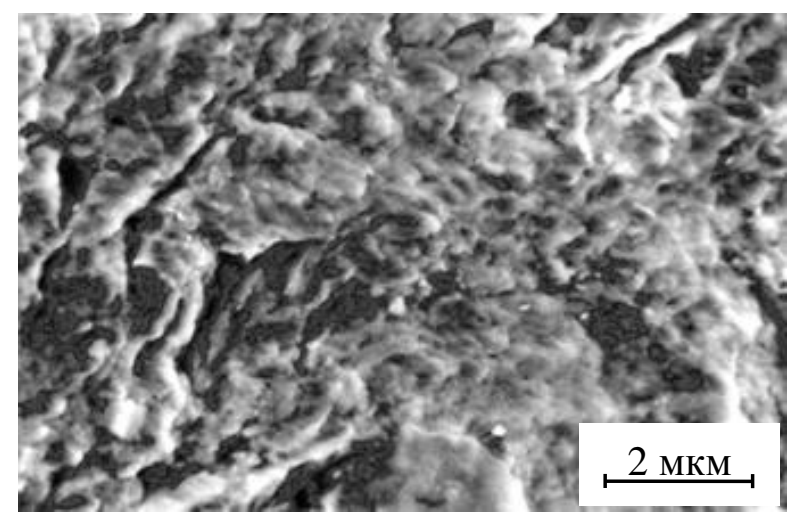

$a$

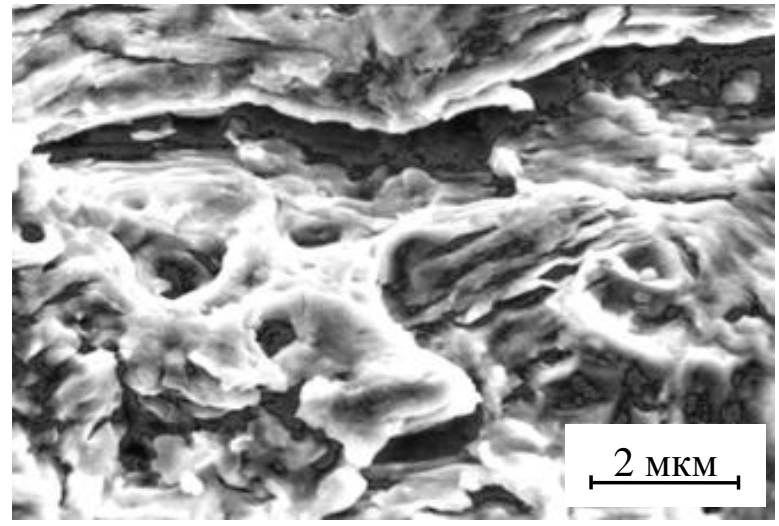

$\sigma$

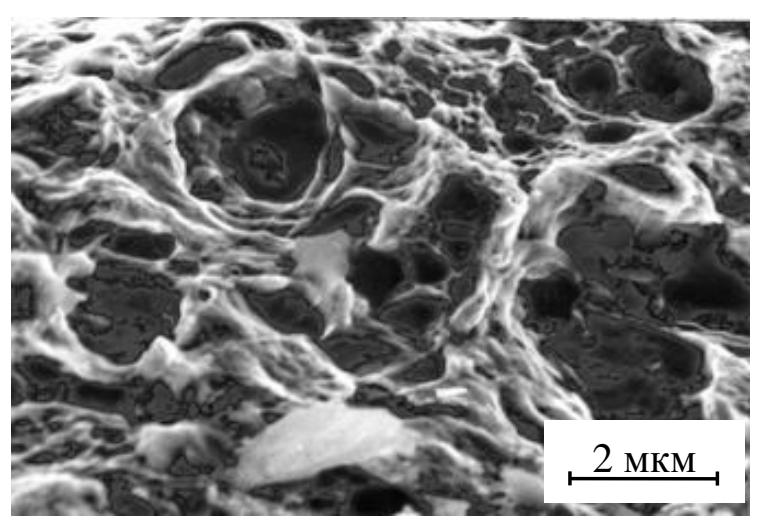

2

Рис. 5. Фрактограммы образцов из стали $05 Г 2 \mathrm{C} 2$, охлажденных в масле от $850^{\circ} \mathrm{C}, \sigma_{a}=420 \mathrm{MПа:}$ $a$ - зона зарождения трещины; $\sigma$ - зона распространения трещины; 6 - зона долома

Характер разрушения в зоне долома чувствителен к напряженному состоянию, реализуемому в образце во время испытания. Для малых амплитуд циклических нагрузок характерен полностью ямочный излом. С увеличением амплитуды нагружения в образце реализуется более жесткое напряженное состояние, что приводит к появлению в некоторых участках зоны долома фасеток скола.

\section{4. Заключение}

Таким образом, проведенное исследование показало, что ДФМС обладает более высоким сопротивлением усталостному разрушению, чем стали с феррито-перлитной структурой. Деформационное старение, сочетающееся с некоторыми технологическими операциями, повышает в значительной мере прочностные характеристики ДФМС при статических испытаниях, но слабо влияет на предел выносливости материала.

\section{Благодарность}

Исследования проведены с использованием оборудования Центра коллективного пользования «Пластометрия» ИМАШ УрО РАН (2. Екатеринбург) по плану работ программь «Арктика» УрО РАН (проект БП 18-9-1-20).

\section{Литература}

1. Ботвина Л. Р. Кинетика разрушения конструкционных материалов. - М. : Наука, 1989. $230 \mathrm{c}$. 
2. Коцаньда С. Усталостное растрескивание металлов / пер. с польского Г. Н. Мехеда; под ред. С. Я. Яремы. - М. : Металлургия, 1990. - 632 с.

3. Bronfin B. M., Shveikin V. P., Shifman A. Z. Influence of type of microstructure on fatigue resistance and fracture of low-carbon, low-alloy steel // Steel in the USSR. - Vol. 16, iss. 10. P. 494-496.

4. Горицкий В. М., Терентьев В. Ф. Структура и усталостное разрушение металлов. М. : Металлургия, 1980. - 208 с.

5. Wasen J., Hamberg K., Karlsson B. The influence of prestrain and ageing on fatigue crack growth in a Dual-Phase Steel // Scripta Metallurgica. - 1984. - Vol. 18, no. 3. - P. 621-624.

6. Pietrowski R., Gasse W. F., and Kenny W. D. Fatigue Properties of Renitrogenized and Dual Phase Steels // International Congress and Exposition, Detroit, Michigan, February 28-March 4, 1983 : SAE Technical Paper Series. - 1983. - No. 2. - P. 1-11.

7. Романив О. Н. Вязкость разрушения конструкционных сталей. - М. : Металлургия, 1979. - $176 \mathrm{c}$.

8. Потемкин А. Н., Викулов А. С., Никитин Д. Е. Усталостное разрушение материалов с позиции различных теорий // Научно-методический электронный журнал «Концепт». 2015. - T. 13. - С. 3311-3315.

9. Фрактографический анализ эксплуатационного разрушения диска ротора высокого давления авиационного газотурбинного двигателя из жаропрочного сплава ЭП741-НП / М. Р. Орлов, О. Г. Оспенникова, В. В. Автаев, А. М. Терехин, Е. В. Филонова // Авиационные материалы и технологии. - 2015. - № S1. - С. 5-12.

10. Numerical and Experimental Approaches to the Evaluation of the Fatigue Life of a Cylindrical Specimen made of the 09G2S Steel / N. A. Drukarenko, I. S. Kamantsev, A. V. Kuznetsov, A. P. Vladimirov, Yu. V. Khudorozhkova // AIP Conf. Proc. - 2017. - Vol. 1915. P. 040010. - DOI: 10.1063/1.5017358. 